\title{
Cerebrovascular reactivity and disease activity in relapsing-remitting multiple sclerosis
}

\author{
Łukasz Smoliński ${ }^{A-F}$, Tomasz Litwin ${ }^{A-F}$, Karolina Kruk ${ }^{B, F}$, Marta Skowrońska ${ }^{A, B, F}$, \\ Iwona Kurkowska-Jastrzębska ${ }^{C, E, F}$, Anna Członkowska ${ }^{\text {A,C,E,F }}$ \\ Second Department of Neurology, Institute of Psychiatry and Neurology, Warszawa, Poland \\ A - research concept and design; $\mathrm{B}$ - collection and/or assembly of data; $\mathrm{C}$ - data analysis and interpretation; \\ $D$ - writing the article; $E$ - critical revision of the article; $F$ - final approval of the article
}

Address for correspondence

Łukasz Smoliński

E-mail: Ismolinski@ipin.edu.pl

Funding sources

None declared

Conflict of interest

None declared

Received on February 25, 2019

Reviewed on June 20, 2019

Accepted on November 25, 2019

Published online on February 19, 2020

Cite as

Smolińskił, Litwin T, Kruk K, Skowrońska M, KurkowskaJastrzębska I, Członkowska A. Cerebrovascular reactivity and disease activity in relapsing-remitting multiple sclerosis. Adv Clin Exp Med. 2020;29(2):183-188.

doi:10.17219/acem/114762

DOI

10.17219/acem/114762

Copyright

Copyright by Author(s)

This is an article distributed under the terms of the

Creative Commons Attribution 3.0 Unported (CC BY 3.0)

(https://creativecommons.org/licenses/by/3.0/)

\section{Abstract}

Background. In multiple sclerosis (MS), insufficient blood supply might worsen energy deficiency of the brain tissue. Thus, cerebrovascular reactivity (CVR), which is the capacity of cerebral circulation to match blood supply to metabolic demand, might be important in MS pathology.

Objectives. The objective of this study was to investigate the relationship of CVR to disease activity and neuroimaging markers of disease progression in patients with MS.

Material and methods. In 43 patients with relapsing remitting MS (RRMS) in clinical remission, 30 patients with a relapse of MS and 30 healthy controls, we measured CVR with transcranial Doppler as a relative change in flow velocity after breath-holding (breath-holding index) and voluntary hyperventilation (hyperventilation index). All patients in remission underwent brain magnetic resonance imaging at baseline and 33 underwent repeated imaging after 12 months, with various brain volume measurements taken.

Results. Cerebrovascular reactivity indices did not differ between patients in remission, patients with a relapse and controls. In patients in remission, CVR did not differ between those with or without contrast-enhancing lesions. In patients with a relapse, glucocorticoids significantly reduced both CVR indices. Cerebrovascular reactivity was not related to brain volume, white matter lesion volume, percent brain volume change, and the change in total white matter lesion volume.

Conclusions. In RRMS, CVR appeared normal and unrelated to disease activity. There was no substantial association of CVR to brain atrophy and accumulation of white matter lesions.

Key words: multiple sclerosis, brain atrophy, cerebral blood flow, cerebrovascular reactivity, transcranial Doppler ultrasonography 


\section{Introduction}

Multiple sclerosis (MS) is an inflammatory disease of the central nervous system, but neurodegenerative mechanisms are also implicated in the pathogenesis of MS. ${ }^{1}$ For example, in MS, histotoxic hypoxia may cause energy deficiency of the brain tissues, which promotes demyelination and axonal loss. ${ }^{2}$ Energy deficiency in MS might be worsened by impaired regulation of cerebral blood flow. Notably, many studies have found diffusely reduced cerebral blood flow in patients with MS compared with healthy age-matched controls. ${ }^{3}$ Moreover, evidence form magnetic resonance imaging (MRI) and histologic studies shows that most white matter (WM) lesions in patients with MS are found in areas with the lowest blood perfusion, the so-called watershed zones. ${ }^{4-6}$ Similarly, in an animal model of MS, demyelinating lesions tend to develop in areas with the worst blood supply. ${ }^{7}$ Thus, cerebrovascular reactivity (CVR), which is the capacity of cerebral circulation to match blood supply to metabolic demand, might be important in MS pathology. Cerebrovascular reactivity changes might be related to autonomic dysfunction, which is common in MS. ${ }^{8,9}$ Usually, CVR is estimated as a relative increase in cerebral flow after increasing the systemic carbon dioxide concentration $\left(\mathrm{CO}_{2}\right.$ inhalation, breath-hold). ${ }^{10,11}$

Reduced CVR may cause insufficient energy supply, particularly to areas with an increased energy demand, such as damaged neurons or WM lesions infiltrated by metabolically active immune cells. ${ }^{12}$ Cerebrovascular reactivity impairment could amplify axonal loss and demyelination. Indeed, during healthy aging, WM areas with the lowest CVR are most susceptible to demyelination. ${ }^{13}$ Similarly, CVR impairment is associated with an increased risk of cerebral ischemia. ${ }^{14}$

To date, few studies have investigated CVR in MS, ${ }^{15-17}$ and one group showed that CVR might be reduced in MS. ${ }^{18,19}$ It remains unclear, however, whether clinical and neuroimaging disease activity is related to CVR in MS. We also do not know whether low CVR increases the risks of brain atrophy and accumulation of demyelinating lesions. Because previous findings on CVR in MS are inconsistent and come from small studies, we checked whether CVR was impaired in MS in a larger group of patients. Moreover, we related CVR to clinical and neuroimaging disease activity and longitudinal changes in brain volume and WM lesion volume.

\section{Material and methods}

\section{Participants}

The study included 43 patients with RRMS in clinical remission, for at least 3 months, who received interferon beta in our clinic, 30 patients with RRMS who received intravenous methylprednisolone ( $1 \mathrm{~g}$ for 3-5 days) due to a relapse (an increase in Extended Disability Status Scale (EDSS) score of at least 1 point), and 30 healthy controls matched for age, sex and cardiovascular risk factors (Table 1). The study was approved by the Bioethics Committee of our Institute, and all participants singed informed consent before enrolment.

\section{Assessment of cerebrovascular reactivity}

Cerebrovascular reactivity was assessed with transcranial Doppler ultrasonography (TCD) at around noon (11 AM to 2 PM). We recorded blood flow velocity in the middle cerebral artery with a 2-megaherz probe fixed with a headband (DWL, Singen, Germany). Blood flow was monitored in either the left or right middle cerebral artery, whichever had a better signal quality. The mean flow velocity (MFV) was calculated over 10-15 heart cycles. During TCD measurements, we continuously recorded the end-tidal carbon dioxide concentration $\left(\mathrm{EtCO}_{2}\right)$ with a capnometer (NMed, Beijing, China). The baseline MFV was recorded after about $5 \mathrm{~min}$ of resting. Then, we recorded the MFV after $2 \mathrm{~min}$ of hyperventilation $\left(\mathrm{EtCO}_{2}\right.$ had to decrease by at least $10 \%$ compared to baseline). After at least $3 \mathrm{~min}$, when the MFV and $\mathrm{EtCO}_{2}$ returned to baseline, we recorded the MFV after $30 \mathrm{~s}$ of breath-hold. Cerebrovascular reactivity was estimated with the breath-hold index (BHI) and $\mathrm{CO}_{2}$-normalized hyperventilation index $\left(\mathrm{HV}_{\triangle \mathrm{CO} 2}\right)$ as follows:

$$
\begin{gathered}
\mathrm{BHI}=\frac{\text { MFV after breat }- \text { hold }- \text { baseline MFV }}{\text { baseline MFV } \times 30} ; \\
\mathrm{HV}_{\Delta \mathrm{CO}_{2}}= \\
=\frac{\text { baseline MFV }- \text { MFV after hyperventilation } \times 100 \%}{\text { baseline MFV } \times \text { EtCO } 2 \text { change from baseline to hyperventilation }}
\end{gathered}
$$

Higher values of both $\mathrm{BHI}$ and $\mathrm{HV}_{\triangle \mathrm{CO} 2}$ indicated greater CVR. In patients with a relapse, TCD measurements were taken on the first and last day of intravenous glucocorticoid treatment, before the first and after the last injection, respectively. In patients in remission, TCD measurements were taken within $1 \mathrm{~h}$ before MRI. Cerebrovascular reactivity was assessed only once in patients in remission and controls. Atherosclerosis of the carotid arteries was ruled out by color Doppler ultrasound.

\section{Magnetic resonance imaging and image analysis}

After the TCD study, patients in remission underwent brain MRI, as part of a routine clinical follow-up. With a $1.5 \mathrm{~T}$ scanner (Philips, Eindhoven, the Netherlands), we acquired 3D T1-weighted images, before and after intravenous gadolinium (Gd) injection, (TR, $25 \mathrm{~ms}$; TE, $4.6 \mathrm{~ms}$; field of view, $240 \times 240 \mathrm{~mm}$; voxel resolution, $0.937 \times 0.937 \times 1 \mathrm{~mm}$ ) and 2D FLAIR images (TR, 11,000 ms; TE, $140 \mathrm{~ms}$; field of view, $0.898 \times 0.898 \times 3 \mathrm{~mm})$. The presence of Gd-enhancing 
$(\mathrm{Gd}(+))$ lesions was assessed by an independent radiologist. Normalized brain volume (NBV) for head size, and normalized volumes of grey matter (GM) and WM were measured based on the T1-weighted images with the SIENAX software. ${ }^{20}$ The lesion-TOADS software was used to measure the total volume of WM lesions (TLV) based on the FLAIR and T1-weighted images ${ }^{21}$; TLV was normalized for head size based on scaling coefficients derived from SIENAX. Before running lesion-TOADS, we extracted brains from whole-head images with the SPECTRE tool and registered the T1-weighted images to the FLAIR images (rigid body registration). ${ }^{21}$ During the study, 33 out of 43 patients in remission had repeated MRI after 12 months (1 patient entered secondary progressive MS, 3 patients were lost to follow-up, 6 patients had less than 12 months of followup). For the 33 patients in remission who had follow-up brain MRI after 12 months, we calculated the percentage brain volume change (PBVC), with the SIENA software, and the TLV change, with lesion-TOADS. ${ }^{20}$

\section{Statistical analysis}

Baseline anthropometric and clinical characteristics were compared between the groups of participants with one-way analysis of variance (ANOVA), the Mann-Whitney U test, and Fisher's exact test, as appropriate. In patients with a relapse of MS, the differences in CVR indices before and after intravenous methylprednisolone treatment were compared with the dependent samples t-test. The Mann-Whitney U test was used to compare CVR indices between patients with or without $\mathrm{Gd}(+)$ lesions. The Pearson coefficient or the Spearman coefficient (rho) was calculated to study correlations between pairs of variables. A value of $\mathrm{p}<0.05$ was considered significant. All analyses were completed in the statistical package $R$ (www.r-project.org).

\section{Results}

\section{Clinical and imaging characteristics}

There were no significant differences in age, proportion of women, and the frequency of cardiovascular risk factors between patients with MS in remission, patients with a relapse of MS and controls (Table 1). Among patients with MS in remission, the studied brain volumes correlated negatively with EDSS, and disease duration correlated positively with TLV (Table 2 ).

\section{Cerebrovascular reactivity}

Neither of the 2 CVR indices, i.e., $\mathrm{BHI}$ and $\mathrm{HV}_{\triangle \mathrm{CO} 2}$, differed significantly between patients with MS in remission, patients with a relapse of MS before intravenous glucocorticoid treatment and controls $(\mathrm{p}=0.56$ for $\mathrm{BHI} ; \mathrm{p}=0.1$ for

Table 1. Clinical characteristics of patients with relapsing-remitting multiple sclerosis in remission, patients during a relapse and controls

\begin{tabular}{|c|c|c|c|c|}
\hline Variable & Controls $(n=30)$ & Remission $(n=43)$ & Relapse $(\mathrm{n}=30)$ & $p$-value \\
\hline Age [years] & $37.2 \pm 8.5$ & $38.2 \pm 8.9$ & $36.1 \pm 8.0$ & $0.60^{\mathrm{a}}$ \\
\hline Women, n (\%) & $23(77)$ & $33(77)$ & $24(80)$ & $0.96^{b}$ \\
\hline Disease duration [years] & - & $6.3 \pm 4.9$ & $10.1 \pm 7.3$ & $0.02^{c}$ \\
\hline Median EDSS (range) & - & $1.5(0-6.0)$ & $4.0(2.0-4.0)$ & $<0.001^{d}$ \\
\hline Initial TLV [mL] & - & $7.4 \pm 5.2$ & - & - \\
\hline TLV change [mL] & - & $0.42 \pm 1.8$ & - & - \\
\hline PBVC & - & $-0.36 \pm 0.49$ & - & - \\
\hline $\mathrm{SBP}[\mathrm{mm} \mathrm{Hg}]$ & $130.7 \pm 11.0$ & $133.9 \pm 15.0$ & $127.7 \pm 14.2$ & $0.17^{\mathrm{a}}$ \\
\hline $\mathrm{DBP}[\mathrm{mm} \mathrm{Hg}]$ & $84.8 \pm 7.0$ & $87.3 \pm 10.3$ & $82.4 \pm 12.0$ & $0.12^{\mathrm{a}}$ \\
\hline Blood glucose [mg/dL] & $100.8 \pm 17.2$ & $98.0 \pm 20.1$ & $99.0 \pm 17.8$ & $0.84^{\mathrm{a}}$ \\
\hline Hypertension, n (\%) & $4(13)$ & $5(12)$ & $2(7)$ & $0.78^{b}$ \\
\hline Smoking, n (\%) & $5(17)$ & $4(9)$ & $4(13)$ & $0.65^{b}$ \\
\hline Dyslipidemia, n (\%) & 0 & $2(5)$ & $1(3)$ & $0.78^{b}$ \\
\hline Diabetes mellitus, n (\%) & 0 & 0 & $1(3)$ & $0.58^{b}$ \\
\hline $\begin{array}{l}\text { Disease-modifying } \\
\text { treatments, } \mathrm{n}(\%)\end{array}$ & - & $\begin{array}{l}\text { IFNß-1a, } 19 \text { (44) } \\
\text { IFNß-1b, } 24 \text { (56) }\end{array}$ & $\begin{array}{c}\text { None, } 20 \text { (67) } \\
\text { GA, } 3 \text { (10) } \\
\text { IFN } 3-1 b, 2(7) \\
\text { DMF, } 2 \text { (7) } \\
\text { TFN, } 1 \text { (3) } \\
\text { FNG, } 1 \text { (3) } \\
\text { LQD, } 1 \text { (3) }\end{array}$ & - \\
\hline
\end{tabular}

The values are means \pm standard deviations (SD) unless otherwise specified; a - one-way analysis of variance (ANOVA); b - Fisher's exact test; c - independent samples t-test; d - Mann-Whitney test; EDSS - Extended Disability Status Scale; TLV - total lesion volume; PBVC - percent brain volume change; SBP - systolic blood pressure; DBP - diastolic blood pressure; IFN - interferon; GA - glatiramer acetate; DMF - dimethyl fumarate; TFN - teriflunomide; FNG - fingolimod. 
Table 2. Correlations between cerebrovascular indices and clinical and imaging variables in patients with multiple sclerosis in remission ( $n=43)$. Significant correlations are in bold

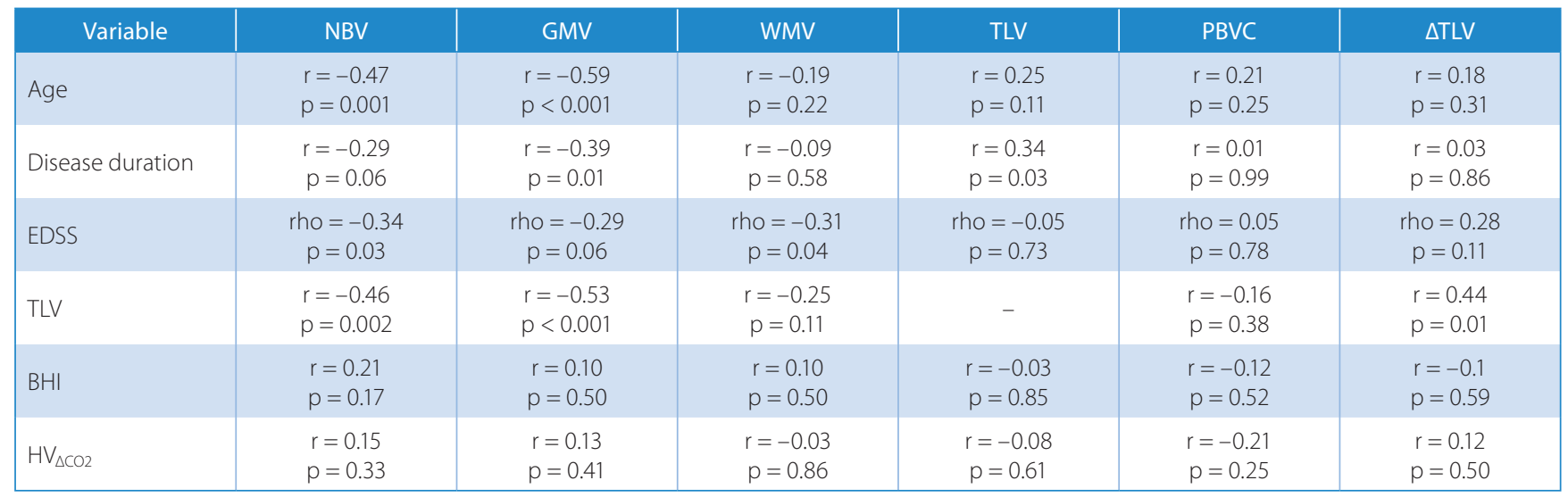

NBV - normalized brain volume; GMV - grey matter volume; WMV - white matter volume; TLV - total lesion volume; PBVC - percent brain volume change; $\triangle T L V$ - change in total lesion volume; EDSS - Extended Disability Status Scale; $\mathrm{BHI}$ - breath-hold indices; $\mathrm{HV}_{\Delta \mathrm{CO} 2}, \mathrm{CO}_{2}-$ normalized hyperventilation indices. All brain volumes were measured in milliliters.

A

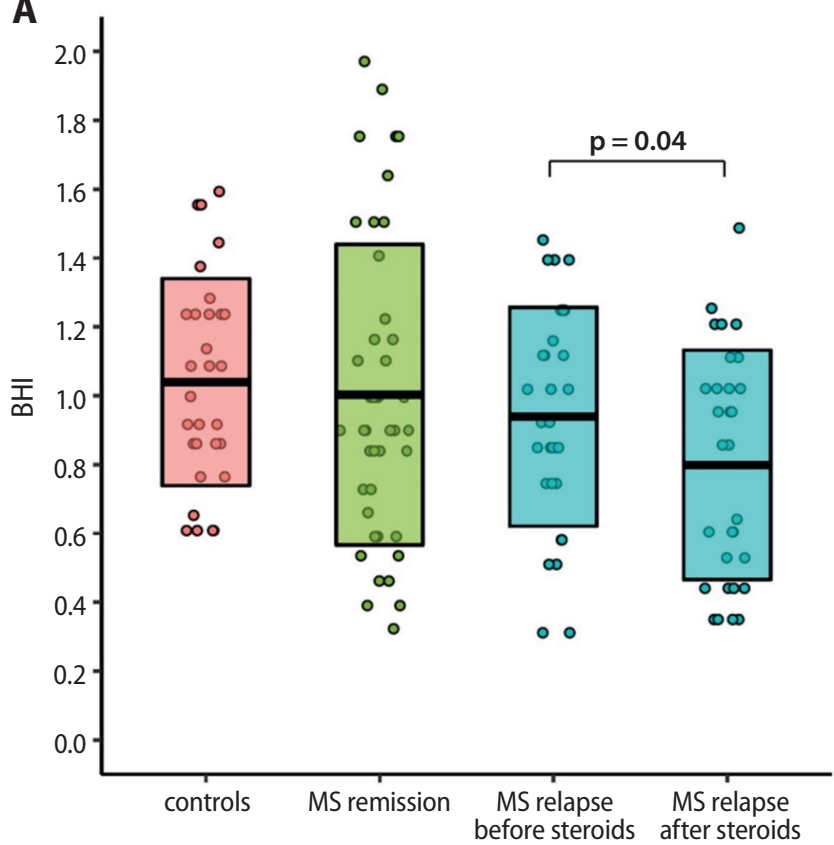

B

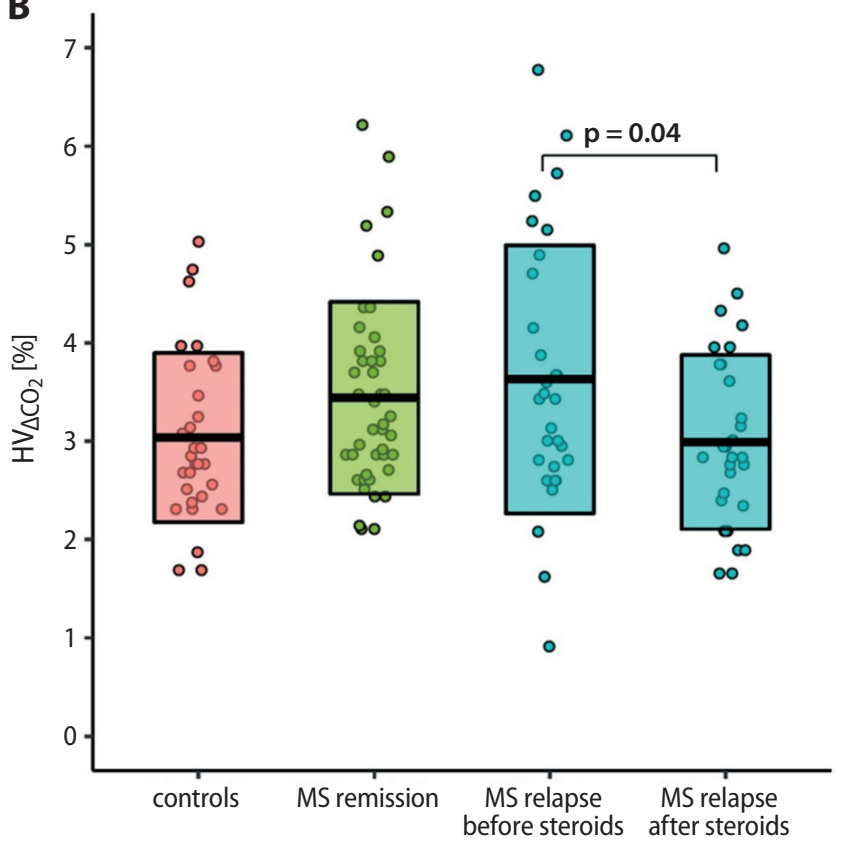

Fig. 1. (A) Breath-hold indices ( $\mathrm{BHI})$ and $(\mathrm{B}) \mathrm{CO}_{2}$-normalized hyperventilation indices $\left(\mathrm{HV}_{\triangle \mathrm{CO}}\right)$ in healthy controls ( $\mathrm{n}=30$ ), patients with multiple sclerosis ( $\mathrm{MS}$ ) in remission $(n=43)$, and patients with a relapse of MS before and after intravenous glucocorticoid treatment $(n=30)$. The middle bar represents the mean, and the upper and lower bars represent standard deviations (SD)

$\mathrm{HV}_{\triangle \mathrm{CO} 2}$; Fig. 1). In patients with a relapse of $\mathrm{MS}$, however, both CVR indices decreased significantly after intravenous glucocorticoid treatment $\left(\mathrm{p}=0.04\right.$ for $\mathrm{BHI}$ and $\mathrm{HV}_{\Delta \mathrm{CO} 2}$; Fig. 1).

Among patients with remission, $\mathrm{BHI}$ and $\mathrm{HV}_{\Delta \mathrm{CO} 2}$ did not differ between those with $(\mathrm{n}=10)$ or without $(\mathrm{n}=33)$ $\mathrm{Gd}(+)$ lesions $\left(\mathrm{p}=0.20\right.$ for $\mathrm{BHI}$, and $\mathrm{p}=0.81$ for $\mathrm{HV}_{\Delta \mathrm{CO} 2}$ ). Among patients in remission, neither of the $2 \mathrm{CVR}$ indices correlated with the brain volumes studied, TLV, PBVC, and TLV change (Table 2). Similarly, BHI and $\mathrm{HV}_{\triangle \mathrm{CO} 2}$ did not correlate significantly with EDSS or disease duration in patients in remission or relapse (data not shown).

\section{Discussion}

Our findings suggest that CVR is normal in RRMS and that it does not change during a relapse of MS or in patients with $\mathrm{Gd}(+)$ lesions. However, we found that treatment with intravenous glucocorticoids reduced CVR in patients with a relapse of MS. In patients with MS in clinical remission, CVR was not related to any of the brain volume measures, including the longitudinal change in brain volume and WM lesion volume. Thus, it seems that there is no substantial relationship between CVR and diseases activity and neuroimaging markers of disease progression in RRMS. 
Our findings are in line with those in most previous studies, which have reported normal CVR in patients with MS. In the study by Uzuner et al. $(n=12)$, CVR measured with TCD did not differ between patients with RRMS and controls. In contrast to our study, those investigators did not find any significant effect of glucocorticoids on CVR. ${ }^{16}$ In another TCD-based study, Khorvash et al. reported that CVR was higher in RRMS than in patients with migraines. However, that study did not include healthy controls. ${ }^{15}$ Similar to our findings, Metzgen et al., who measured CVR with blood oxygen level-dependent (BOLD) functional MRI (fMRI) after $\mathrm{CO}_{2}$ inhalation, observed normal CVR in MS and did not find CVR to correlate with brain volume and WM lesion volume. ${ }^{17}$ Those investigators showed that CVR was reduced in patients with MS and cognitive impairment, but this relationship is found in other diseases as well. ${ }^{22}$ To date, based on arterial spin labeling (ASL) fMRI, only 1 group has reported reduced CVR in MS. Moreover, that group found that CVR correlated negatively with WM lesion volume and GM atrophy. ${ }^{18}$ ASL-based fMRI may be the best method to study CVR impairment in MS; however, CVR measurements based on ASL and BOLD fMRI usually lead to similar conclusions. ${ }^{23,24}$ Moreover, in Alzheimer's disease, reduced CVR has been demonstrated with many techniques, including BOLD, ASL and TCD. ${ }^{25}$

Marshall et al. hypothesized that CVR might be reduced in MS due to habituation of cerebral vasculature to chronically increased nitric oxide concentrations. ${ }^{18}$ However, nitric oxide seems essential for hypercapnia-induced cerebral vasodilation, ${ }^{26}$ and consequently for CVR, and we were not able to find any previous evidence that nitric oxide, when chronically increased, like in MS, ${ }^{27}$ has an opposing effect. ${ }^{28,29}$ In contrast, scavenging of nitric oxide by reactive oxygen species (ROS) reduces vasodilation, which could occur in MS. ${ }^{30,31}$

Different effects of inflammation, such as increased oxidative stress, might reduce CVR. For example, in patients with diabetes, higher concentrations of inflammatory markers were associated with reduced CVR. ${ }^{32}$ In our study, CVR was similar in patients with clinical remission and a relapse of MS, and $\mathrm{Gd}(+)$ lesions were not associated with reduced CVR. However, we did not measure inflammatory markers in our study. We observed that treatment with glucocorticoids, which have anti-inflammatory effects, not only did not improve CVR, but significantly reduced it. Similarly, in patients with diabetes, reduced CVR was associated with increased concentrations of endogenous cortisol. ${ }^{32}$ We suspect that the glucocorticoidinduced reduction of CVR might be due to a direct effect of glucocorticoids on cerebral vessels. For instance, glucocorticoids decrease endothelial synthesis of nitric oxide, and they increase the sensitivity of vascular smooth muscle cells to endogenous vasoconstrictions, such as norepinephrine. ${ }^{33}$ However, we measured CVR twice in patients with a relapse only and not in those in remission or in controls. Therefore, the effect of glucocorticoids on CVR that we observed might be due to physiological variability or becoming familiar with the procedure by participants.

Because CVR is a measure of cerebral metabolic reserve, we suspected that reduced CVR would be related to greater brain atrophy and greater accumulation of WM lesions, particularly because most WM lesions in MS occur in areas with reduced blood flow and reduced CVR. ${ }^{4-6,13}$ However, in our study, CVR was not related to brain volume reduction and the change in WM lesion volume.

Our study had limitations. First, it included a relatively small group of patients. However, with over 70 patients with RRMS, our study is the largest study on CVR in MS to date. Additionally, the included number of patients allowed us to observe the well-established relationships in MS, such as the correlation between EDSS, disease duration, and brain volume. Because we did not include patients with progressive MS, our findings may not hold true for these patients. Second, we included patients with MS in remission who received interferon beta only. Although the effect of interferon beta on CVR is unknown, a study among 5 patients with MS showed that interferon beta increased blood flow in the basal ganglia. ${ }^{34}$ Moreover, interferon beta, similar to other diseasemodifying treatment, slows the rate of brain atrophy and lesion accumulation in MS. ${ }^{35}$ Thus, the potential relationship between CVR and brain atrophy along with lesion accumulation might be abolished by treatment with interferon beta. Third, some investigators regard breath-holding a less reliable hypercapnic stimulus than $\mathrm{CO}_{2}$ inhalation. ${ }^{36}$ Others, however, have found these 2 stimuli equivalent for estimating CVR. ${ }^{37}$ Moreover, fMRI might be better than TCD for measuring CVR, but there is a good agreement between these 2 approaches. ${ }^{38}$ In addition to breath-holding, we used voluntary hyperventilation to measure $\mathrm{CO}_{2}$-normalized CVR. The relationships between CVR and other variables in our study were consistent when assessed with the 2 CVR indices $\left(\mathrm{BHI}, \mathrm{HV}_{\Delta \mathrm{CO} 2}\right)$. Apart from the use of 2 vasoactive stimuli to measure CVR, the strengths of our study include enrolment of patients in remission and a relapse of MS, measurement of CVR before and after glucocorticoid treatment, and longitudinal MRI analyses. We also measured CVR in all participants at the same time of the day, because CVR may decrease by over a third from morning to evening. ${ }^{29}$

We conclude that CVR is normal and is not related to disease activity in patients with RRMS. Moreover, CVR seems unrelated to the accumulation of WM lesions and brain atrophy in these patients. It would be worthwhile to verify our findings with fMRI-based CVR measurements, preferably in larger studies that would enroll patients with progressive MS.

\section{ORCID iDs}

Łukasz Smoliński (D) https://orcid.org/0000-0003-1614-7069 Tomasz Litwin (D) https://orcid.org/0000-0003-2670-9651 Karolina Kruk (D) https://orcid.org/0000-0003-0149-5212 Marta Skowrońska (D) https://orcid.org/0000-0002-0826-7821 Iwona Kurkowska-Jastrzębska (D) https://orcid.org/0000-0001-6553-9080 Anna Członkowska (D) https://orcid.org/0000-0002-1956-1866 


\section{References}

1. Mahad DH, Trapp BD, Lassmann H. Pathological mechanisms in progressive multiple sclerosis. Lancet Neurol. 2015;14(2):183-193. doi:10. 1016/S1474-4422(14)70256-X

2. Lassmann H. Multiple sclerosis pathology. Cold Spring Harb Perspect Med. 2018;8(3):a028936. doi:10.1101/cshperspect.a028936

3. D'haeseleer M, Hostenbach S, Peeters I, et al. Cerebral hypoperfusion: A new pathophysiologic concept in multiple sclerosis? J Cereb Blood Flow Metab. 2015;35(9):1406-1410. doi:10.1038/jcbfm.2015.131

4. Holland CM, Charil A, Csapo I, et al. The relationship between normal cerebral perfusion patterns and white matter lesion distribution in 1,249 patients with multiple sclerosis. J Neuroimaging. 2012;22(2): 129-136. doi:10.1111/j.1552-6569.2011.00585.x

5. Narayana PA, Zhou Y, Hasan KM, Datta S, Sun X, Wolinsky JS. Hypoperfusion and T1-hypointense lesions in white matter in multiple sclerosis. Mult Scler. 2014;20(3):365-373. doi:10.1177/1352458513495936

6. Haider L, Zrzavy T, Hametner S, et al. The topograpy of demyelination and neurodegeneration in the multiple sclerosis brain. Brain. 2016;139(Pt 3):807-815. doi:10.1093/brain/awv398

7. Desai RA, Davies AL, Tachrount M, et al. Cause and prevention of demyelination in a model multiple sclerosis lesion. Ann Neurol. 2016:79(4):591-604. doi:10.1002/ana.24607

8. Tantucci C, Bottini P, Fiorani C, et al. Cerebrovascular Reactivity and Hypercapnic Respiratory Drive in Diabetic Autonomic Neuropathy. 2001. http://www.jap.org. Accessed June 2, 2019.

9. Adamec I, Habek M. Autonomic dysfunction in multiple sclerosis. Clin Neurol Neurosurg. 2013;115(Suppl 1):S73-S78. doi:10.1016/j.clineuro. 2013.09.026

10. Keage HAD, Churches OF, Kohler M, et al. Cerebrovascular function in aging and dementia: A systematic review of transcranial Doppler studies. Dement Geriatr Cogn Dis Extra. 2012;2(1):258-270. doi: $10.1159 / 000339234$

11. Blair GW, Doubal FN, Thrippleton MJ, Marshall I, Wardlaw JM. Magnetic resonance imaging for assessment of cerebrovascular reactivity in cerebral small vessel disease: A systematic review. J Cereb Blood Flow Metab. 2016;36(5):833-841. doi:10.1177/0271678X16631756

12. Campbell GR, Worrall JT, Mahad DJ. The central role of mitochondria in axonal degeneration in multiple sclerosis. Mult Scler J. 2014;20(14): 1806-1813. doi:10.1177/1352458514544537

13. Mandell DM, Han JS, Poublanc J, et al. Selective reduction of blood flow to white matter during hypercapnia corresponds with leukoaraiosis. Stroke. 2008;39(7):1993-1998. doi:10.1161/STROKEAHA.107.501692

14. Silvestrini $M$, Vernieri F, Pasqualetti $P$, et al. Impaired cerebral vasoreactivity and risk of stroke in patients with asymptomatic carotid artery stenosis. JAMA. 2000;283(16):2122-2127. http://www.ncbi.nlm. nih.gov/pubmed/10791504. Accessed August 6, 2018.

15. Khorvash F, Masaeli A, Shaygannejad V, Saadatnia M. Vasomotor reac tivity comparison in multiple sclerosis patients with white matter lesions and nonmultiple sclerosis subjects with white matter lesions in brain magnetic resonance imaging. Adv Biomed Res. 2016;5:23. doi:10.4103/2277-9175.175916

16. Uzuner N, Ozkan S, Cinar N. Cerebrovascular reactivity in multiple sclerosis patients. Mult Scler J. 2007;13(6):737-741. doi:10.1177/ 1352458506074645

17. Metzger A, Le Bars E, Deverdun J, et al. Is impaired cerebral vasoreactivity an early marker of cognitive decline in multiple sclerosis patients? Eur Radiol. 2018;28(3):1204-1214. doi:10.1007/s00330-0175068-5

18. Marshall $\mathrm{O}, \mathrm{Lu} \mathrm{H}$, Brisset J-C, et al. Impaired cerebrovascular reactivity in multiple sclerosis. JAMA Neurol. 2014;71(10):1275-1281. doi:10.1001/ jamaneurol.2014.1668

19. Marshall O, Chawla S, Lu H, Pape L, Ge Y. Cerebral blood flow modulation insufficiency in brain networks in multiple sclerosis: A hypercapnia MRI study. J Cereb Blood Flow Metab. 2016;36(12):2087-2095. doi:10.1177/0271678X16654922
20. Smith SM, Zhang Y, Jenkinson M, et al. Accurate, robust, and automated longitudinal and cross-sectional brain change analysis. Neuroimage. 2002;17(1):479-489. http://www.ncbi.nlm.nih.gov/pubmed/ 12482100. Accessed February 12, 2017.

21. Shiee N, Bazin P-L, Ozturk A, Reich DS, Calabresi PA, Pham DL. A topology-preserving approach to the segmentation of brain images with multiple sclerosis lesions. Neuroimage. 2010;49(2):1524-1535. doi:10. 1016/j.neuroimage.2009.09.005

22. Catchlove SJ, Pipingas A, Hughes ME, Macpherson H. Magnetic resonance imaging for assessment of cerebrovascular reactivity and its relationship to cognition: A systematic review. BMC Neurosci. 2018; 19(1):21. doi:10.1186/s12868-018-0421-4

23. Zhou Y, Rodgers ZB, Kuo AH. Cerebrovascular reactivity measured with arterial spin labeling and blood oxygen level dependent techniques. Magn Reson Imaging. 2015;33(5):566-576. doi:10.1016/j.mri. 2015.02.018

24. Mandell DM, Han JS, Poublanc J, et al. Mapping cerebrovascular reactivity using blood oxygen level-dependent MRI in patients with arterial steno-occlusive disease: Comparison with arterial spin labeling MRI. Stroke. 2008;39(7):2021-2028. doi:10.1161/STROKEAHA.107.506709

25. Smoliński Ł, Członkowska A. Cerebral vasomotor reactivity in neurodegenerative diseases. Neurol Neurochir Pol. 2016;50(6):455-462. doi:10.1016/j.pjnns.2016.07.011

26. Lavi S, Egbarya R, Lavi R, Jacob G. Role of nitric oxide in the regulation of cerebral blood flow in humans chemoregulation versus mechanoregulation. Circulation. 2003;107(14):1901-1905.

27. Smith $\mathrm{KJ}$, Lassmann $\mathrm{H}$. The role of nitric oxide in multiple sclerosis. Lancet Neurol. 2002;1(4):232-241.

28. Toda N, Ayajiki K, Okamura T. Cerebral blood flow regulation by nitric oxide: Recent advances. Pharmacol Rev. 2009;61(1):62-97. doi:10.1124/ pr.108.000547

29. Meadows GE, Kotajima F, Vazir A, et al. Overnight changes in the cerebral vascular response to isocapnic hypoxia and hypercapnia in healthy humans: Protection against stroke. Stroke. 2005;36(11): 2367-2372. doi:10.1161/01.STR.0000185923.49484.0f

30. Sweazea KL, Lekic M, Walker BR. Comparison of mechanisms involved in impaired vascular reactivity between high sucrose and high fat diets in rats. Nutr Metab (Lond). 2010;7(1):48. doi:10.1186/1743-7075-7-48

31. Ohl K, Tenbrock K, Kipp M. Oxidative stress in multiple sclerosis: Central and peripheral mode of action. Exp Neurol. 2016;277:58-67. doi:10.1016/j.expneurol.2015.11.010

32. Chung CC, Pimentel D, Jor'dan AJ, Hao Y, Milberg W, Novak V. Inflammation-associated declines in cerebral vasoreactivity and cognition in type 2 diabetes. Neurology. 2015;85(5):450-458. doi:10.1212/ WNL.0000000000001820

33. Yang S, Zhang L. Glucocorticoids and vascular reactivity. Curr VasC Pharmacol. 2004;2(1):1-12. http://www.ncbi.nlm.nih.gov/pubmed/ 15320828. Accessed June 23, 2018.

34. Mackowiak PA, Siegel E, Wasserman SS, Cameron E, Nessaiver MS, Bever CC. Effects of IFN- $\beta$ on human cerebral blood flow distribution. J Interf Cytokine Res. 1998;18(6):393-397. doi:10.1089/jir.1998.18.393

35. Zivadinov R, Locatelli L, Cookfair D, et al. I nterferon beta-1a slows progression of brain atrophy in relapsing-remitting multiple sclerosis predominantly by reducing gray matter atrophy. Mult Scler J. 2007;13(4):490-501. doi:10.1177/1352458506070446

36. Fierstra J, Sobczyk O, Battisti-Charbonney A, et al. Measuring cerebrovascular reactivity: What stimulus to use? J Physiol. 2013;591(23): 5809-5821. doi:10.1113/jphysiol.2013.259150

37. Kastrup A, Krüger G, Neumann-Haefelin T, Moseley ME. Assessment of cerebrovascular reactivity with functional magnetic resonance imaging: Comparison of $\mathrm{CO}_{2}$ and breath holding. Magn Reson Imaging. 2001; 19(1):13-20.

38. Herrera CRC, Beltramini GC, Avelar WM, Lima FO, Li LM. Cerebral vasomotor reactivity assessment using transcranial Doppler and MRI with apnea test. Brazilian J Med Biol Res. 2016;49(11):e5437. 